\title{
Stereotactic radiosurgery for cerebellar arteriovenous malformations: an international multicenter study
}

\author{
Or Cohen-Inbar, MD, PhD, ${ }^{1}$ Robert M. Starke, MD, MSc, ${ }^{1,9}$ Hideyuki Kano, MD, PhD, ${ }^{2}$ \\ Gregory Bowden, MD, ${ }^{2}$ Paul Huang, MD, ${ }^{3}$ Rafael Rodriguez-Mercado, MD, ${ }^{4}$ Luis Almodovar, MD, ${ }^{4}$ \\ Inga S. Grills, MD, ${ }^{5}$ David Mathieu, MD, ${ }^{6}$ Danilo Silva, MD, ${ }^{7}$ Mahmoud Abbassy, MD, ${ }^{7}$ \\ Symeon Missios, MD, ${ }^{7}$ John Y. K. Lee, MD, ${ }^{8}$ Gene H. Barnett, MD, MBA, ${ }^{7}$ Douglas Kondziolka, MD, ${ }^{3}$ \\ L. Dade Lunsford, MD, ${ }^{2}$ and Jason P. Sheehan, MD, PhD'

\begin{abstract}
'Department of Neurosurgery and Gamma-Knife Center, University of Virginia Health System, Charlottesville, Virginia; 2Department of Neurosurgery, University of Pittsburgh, Pennsylvania; ${ }^{3}$ Department of Neurosurgery, New York University Langone Medical Center, New York, New York; ' ${ }^{4}$ Department of Neurosurgery, University of Puerto Rico, San Juan, Puerto Rico; ${ }^{5}$ Department of Radiation Oncology, Beaumont Health System, Royal Oak, Michigan; ${ }^{6}$ Department of Neurosurgery, University of Sherbrooke, Centre de Recherche Clinique Étienne-LeBel, Sherbrooke, Quebec, Canada; ${ }^{7}$ Rose-Ella Burkhardt Brain Tumor and Neuro-oncology Center, Cleveland Clinic, Cleveland, Ohio; ${ }^{8}$ Department of Neurosurgery, University of Pennsylvania, Philadelphia, Pennsylvania; and ${ }^{\circ}$ Department of Neurological Surgery and Radiology, University of Miami, Florida
\end{abstract}

OBJECTIVE Cerebellar arteriovenous malformations (AVMs) represent the majority of infratentorial AVMs and frequently have a hemorrhagic presentation. In this multicenter study, the authors review outcomes of cerebellar AVMs after stereotactic radiosurgery (SRS).

METHODS Eight medical centers contributed data from 162 patients with cerebellar AVMs managed with SRS. Of these patients, $65 \%$ presented with hemorrhage. The median maximal nidus diameter was $2 \mathrm{~cm}$. Favorable outcome was defined as AVM obliteration and no posttreatment hemorrhage or permanent radiation-induced complications (RICs). Patients were followed clinically and radiographically, with a median follow-up of 60 months (range 7-325 months).

RESULTS The overall actuarial rates of obliteration at 3, 5, 7, and 10 years were $38.3 \%, 74.2 \%, 81.4 \%$, and $86.1 \%$, respectively, after single-session SRS. Obliteration and a favorable outcome were more likely to be achieved in patients treated with a margin dose greater than $18 \mathrm{~Gy}$ ( $p<0.001$ for both), demonstrating significantly better rates $(83.3 \%$ and $79 \%$, respectively). The rate of latency preobliteration hemorrhage was $0.85 \% / y e a r$. Symptomatic post-SRS RICs developed in $4.5 \%$ of patients $(n=7)$. Predictors of a favorable outcome were a smaller nidus $(p=0.0001)$, no pre-SRS embolization $(p=0.003)$, no prior hemorrhage $(p=0.0001)$, a higher margin dose $(p=0.0001)$, and a higher maximal dose $(p=0.009)$. The Spetzler-Martin grade was not found to be predictive of outcome. The Virginia Radiosurgery AVM Scale score $(p=0.0001)$ and the Radiosurgery-Based AVM Scale score $(p=0.0001)$ were predictive of a favorable outcome.

CONCLUSIONS SRS results in successful obliteration and a favorable outcome in the majority of patients with cerebellar AVMs. Most patients will require a nidus dose of higher than $18 \mathrm{~Gy}$ to achieve these goals. Radiosurgical and not microsurgical scales were predictive of clinical outcome after SRS.

https://thejns.org/doi/abs/10.3171/2016.7.JNS161208

KEY WORDS Gamma Knife; arteriovenous malformation; cerebellar; stereotactic radiosurgery; vascular disorders

ABBREVIATIONS AVM = arteriovenous malformation; GKRS = Gamma Knife radiosurgery; IGKRF = International Gamma Knife Research Foundation; RBAS = Radiosurgery-Based AVM Scale; RIC = radiosurgery-induced complication; SRS = stereotactic radiosurgery; VRAS = Virginia Radiosurgery AVM Scale.

SUBMITTED May 10, 2016. ACCEPTED July 13, 2016.

INCLUDE WHEN CITING Published online September 30, 2016; DOI: 10.3171/2016.7.JNS161208. 
A RTERIOVENOUS malformations (AVMs) are congenital vascular malformations with an incidence of $1: 100,000 .{ }^{1}$ Infratentorial AVMs were first reported by Clingenstein in $1908 .^{21}$ Cerebellar AVMs represent the majority of infratentorial AVMs. ${ }^{3}$ These rare lesions account for $7 \%-15 \%$ of all intracranial AVMs in most large clinical series. ${ }^{3}$ Cerebellar AVMs have a notoriously high rate of hemorrhagic presentation, approaching 70\%-90\%., 3,16,29,33 This figure is almost double the initial hemorrhage rates seen for supratentorial AVMs. ${ }^{17}$ As such, posterior fossa AVMs have a mortality rate as high as $60 \%$ for patients presenting with a nidus-related hemorrhage. ${ }^{4}$ The management of these neurovascular lesions is complicated by the anatomical constraints of the posterior fossa and the concentration of eloquent neurological structures. The smaller and limited volume of the posterior fossa does not allow for much volume expansion (due to AVM nidus hemorrhage or edema). Clinical manifestation and neurological decompensation ensues earlier than for equal-volume supratentorial hemorrhages. $7,20,28$

Unlike brainstem AVMs, cerebellar AVMs are often more superficially located and, in select cases, amenable to resection. ${ }^{7}$ Despite the immediate elimination of nidus hemorrhage when resection achieves complete AVM obliteration, the morbidity and mortality associated with attempted surgical removal have prompted evaluation of other management modalities. ${ }^{29}$

The goal of stereotactic radiosurgery (SRS) is complete nidus vascular closure, thereby eliminating risk of future hemorrhage. ${ }^{27,40}$ Obliteration rates are reported to vary between $70 \%$ and $80 \%{ }^{14,20}$ with a relatively low risk profile for adverse radiation effects, ${ }^{22}$ even when treating deep lesions that are less suitable for resection. However, the obliteration and complication rates afforded by SRS for cerebellar AVMs are mostly composed of a single institution's experience and are subject to individual selection bias. $7,14,20,22,40$ The goals of this multicenter study were to assess the outcomes after SRS for cerebellar AVMs and to evaluate factors that affect the results.

\section{Methods \\ Patient Population}

Eight medical centers participating through the International Gamma Knife Research Foundation (IGKRF) obtained individual institutional review board approvals to participate in this study. A total of 162 patients identified as having cerebellar AVMs underwent Gamma Knife radiosurgery (GKRS) between 1988 and 2015. At each center, retrospective review of clinical and radiological patient outcome parameters was performed. The following centers contributed data for this study: the University of Virginia (67 patients), the University of Pittsburgh (58 patients), Cleveland Clinic Foundation (13 patients), New York University (5 patients), Beaumont Health System (5 patients), University of Sherbrooke, Centre de Recherché Clinique (5 patients), University of Pennsylvania (5 patients), and the University of Puerto Rico (4 patients).

The records of AVM patients who underwent Gamma Knife (Elekta AB) SRS during the period 1988-2015 were evaluated by clinicians at each center for study inclusion.
A database with selected variables was created and sent to all participating centers. Participating centers reviewed the medical records of their patients, entered data, and removed all patient identifiers from the database. Pooled and de-identified data were screened by the IGKRF study coordinator for errors. Data were verified for compliance with protection of patient information. Any uncertainties or ambiguities in the data were addressed by the contributing center.

Patients were included in the study if they had a cerebellar AVM treated with SRS and a minimum of 6 months of neuroimaging and clinical follow-up after the procedure. Patients with radiosurgery-induced complications (RICs) or hemorrhage within the first 6 months after SRS were also included. Patients treated with volume-staged or hypofractionated SRS were excluded. Demographic, medical, and clinical parameters at different time points were logged. Detailed clinical and radiological presentations as well as outcome parameters were recorded. Neurological examination, complications, and deficits were recorded.

\section{Cohort Overview}

The specific patient and tumor attributes are detailed in Table 1. A total of 162 patients harboring cerebellar AVMs were included in the cohort. Males formed 50\% of the cohort $(\mathrm{n}=81)$, and the median age was 44 years (range 6-99 years). The median nidus volume was $2 \mathrm{ml}$ (range $0.1-22 \mathrm{ml}$ ), and the median maximal nidus diameter was $2 \mathrm{~cm}$ (range $1-5 \mathrm{~cm}$ ). The majority of patients had a Spetzler-Martin ${ }^{31}$ Grade II AVM $(48.8 \%, \mathrm{n}=79)$. The majority of AVMs $(60.5 \%, \mathrm{n}=98)$ had a deep venous drainage. The most common Virginia Radiosurgery AVM Scale (VRAS) score ${ }^{35}$ noted was 1 (AVM volume $<2 \mathrm{ml}$, no history of hemorrhage, and not in an eloquent area) $(38.3 \%, \mathrm{n}=62)$, followed by VRAS Score $2(32.7 \%$, $\mathrm{n}=53)$, and VRAS Score $3(14.2 \%, \mathrm{n}=23)$. The most common Radiosurgery-Based AVM Scale (RBAS) score ${ }^{25}$ noted was RBAS as score of 2 (calculated as $0.1 \times$ AVM volume + $0.02 \times$ patient age +0.3$)(41.9 \%, \mathrm{n}=68)$, followed by RBAS Score $1(27.8 \%, \mathrm{n}=45)$ and RBAS Score $3(23.5 \%, \mathrm{n}=38)$.

As depicted in Table $1,65.4 \%(n=106)$ of patients experienced an AVM-related hemorrhage prior to SRS, and $19.8 \%(\mathrm{n}=32$ ) of AVMs had an accompanying aneurysm diagnosed and treated. The most common presenting feature was intracranial hemorrhage in $65.4 \%(\mathrm{n}=106)$ (Table 1). Prior resection of the nidus was performed in $9.9 \%(n=16)$ of patients, $9.9 \%(n=16)$ of patients received prior radiation therapy, and $22.8 \%(\mathrm{n}=37)$ of patients underwent prior AVM nidus embolization. For $60.5 \%(\mathrm{n}=$ 98) of patients, SRS was performed as a primary treatment (i.e., upfront SRS).

\section{Radiosurgical Technique}

Gamma Knife models U, B, C, 4C, and Perfexion were used through the years, depending on the technology available at the time of SRS at each participating center. The Leksell model G stereotactic frame (Elekta AB) was applied using local anesthetic supplemented by additional intravenous conscious sedation as needed. High-resolu- 
TABLE 1. Patient-related parameters ( $n=162$ patients)

\begin{tabular}{|c|c|}
\hline Characteristic & Value \\
\hline Median age (range) in yrs & $44(6-99)$ \\
\hline Sex (F/M) & $81: 81$ \\
\hline \multicolumn{2}{|l|}{ Nidus size } \\
\hline Median vol (range) in $\mathrm{ml}$ & $2(0.1-22)$ \\
\hline Median max diameter (range) in $\mathrm{cm}$ & $2(1-5)$ \\
\hline Median delay from diagnosis to SRS (range) in mos & $5(0-251)$ \\
\hline \multicolumn{2}{|l|}{ Size } \\
\hline Small $(<3 \mathrm{~cm})$ & $141(87 \%)$ \\
\hline Medium $(3-6 \mathrm{~cm})$ & $20(12.3 \%)$ \\
\hline Large $(>6 \mathrm{~cm})$ & $1(0.6 \%)$ \\
\hline \multicolumn{2}{|l|}{ Eloquence of adjacent brain } \\
\hline Noneloquent & $105(64.8 \%)$ \\
\hline Eloquent & $57(35.2 \%)$ \\
\hline \multicolumn{2}{|l|}{ Venous drainage } \\
\hline Superficial only & $64(39.5 \%)$ \\
\hline Deep & $98(60.5 \%)$ \\
\hline \multicolumn{2}{|l|}{ Spetzler-Martin grade } \\
\hline I & $38(23.5 \%)$ \\
\hline ॥ & $79(48.8 \%)$ \\
\hline III & $38(23.5 \%)$ \\
\hline IV & $7(4.3 \%)$ \\
\hline \multicolumn{2}{|l|}{ VRAS } \\
\hline 0 & $13(8 \%)$ \\
\hline 1 & $62(38.3 \%)$ \\
\hline 2 & $53(32.7 \%)$ \\
\hline 3 & $23(14.2 \%)$ \\
\hline 4 & $11(6.8 \%)$ \\
\hline \multicolumn{2}{|l|}{ RBAS } \\
\hline 0 & $11(6.8 \%)$ \\
\hline 1 & $45(27.8 \%)$ \\
\hline 2 & $68(41.9 \%)$ \\
\hline 3 & $38(23.5 \%)$ \\
\hline Prior intracranial hemorrhage & $106(65.4 \%)$ \\
\hline Accompanied by aneurysm & $32(19.8 \%)$ \\
\hline \multicolumn{2}{|l|}{ Presentation } \\
\hline Asymptomatic & $10(6.2 \%)$ \\
\hline Headache & $31(19.1 \%)$ \\
\hline Seizure & $2(1.2 \%)$ \\
\hline Neurological deficit & $13(8 \%)$ \\
\hline Bleeding & $106(65.4 \%)$ \\
\hline \multicolumn{2}{|l|}{ Prior surgery } \\
\hline Microsurgical resection of nidus & $16(9.9 \%)$ \\
\hline VPS or EVD & $1(0.6 \%)$ \\
\hline \multicolumn{2}{|l|}{ No. of prior ops } \\
\hline 1 & $16(9.9 \%)$ \\
\hline 2 & $1(0.6 \%)$ \\
\hline 3 & $2(1.2 \%)$ \\
\hline 4 & $1(0.6 \%)$ \\
\hline Prior embolization & $37(22.8 \%)$ \\
\hline
\end{tabular}

CONTINUED IN NEXT COLUMN »
» CONTINUED FROM PREVIOUS COLUMN

TABLE 1. Patient-related parameters ( $n=162$ patients)

\begin{tabular}{lc}
\hline \multicolumn{1}{c}{ Characteristic } & Value \\
\hline Prior radiation therapy & $16(9.9 \%)$ \\
\hline Median follow-up (range) in mos & $60(7-325)$ \\
\hline Clinical & $31(6-220)$ \\
\hline MRI & $36(6-325)$ \\
\hline Angiography & \\
\hline SRS parameters & $22(10-35)$ \\
\hline Median radiation dose (range) in Gy & $40(18-50)$ \\
\hline Margin & $50(45-100)$ \\
\hline Max & $2(1-18)$ \\
\hline Median isodose level (range) as \%
\end{tabular}

$E V D=$ external ventricular drain; $\max =$ maximal; VPS = ventriculoperitoneal shunt.

tion stereotactic MRI was then performed. In instances in which MRI was not feasible or when MRI distortion was a concern, a stereotactic CT scan was obtained. Thinslice axial and/or coronal plane images were obtained after intravenous contrast administration. Stereotactic cerebral angiography was incorporated in treatment planning for nidus definition. Multidisciplinary radiosurgery dose planning was then performed by the neurosurgeon in conjunction with a radiation oncologist and medical physicist.

In this series, the median margin and maximal doses delivered to the AVM margin were 22 Gy (range 10-35 Gy) and 40 Gy (range 18-50 Gy), respectively. Dose selection relied on the factors of nidus volume, prior neurological deficits, proximity to critical structures, and history, if any, of prior fractionated radiation therapy. Radiosurgical parameters are detailed in Table 1.

\section{Clinical and Radiological Assessment After SRS}

Following SRS, clinical and neuroimaging evaluations were generally performed at follow-up intervals of 6 months for the first 2 years after SRS and then yearly thereafter. Patient evaluations included neurological examination and neuroimaging at the respective treating center. Symptoms and signs were followed and logged, imaging was reviewed, and appropriate additional medical/surgical treatment was instituted. When there was no patent nidus shown on MRI and obliteration was suspected, the patient typically underwent diagnostic cerebral angiography to confirm nidus obliteration. If the AVM was still patent 3 to 4 years after initial SRS, additional treatment with SRS was employed in select patients. However, outcome was assessed from the time of initial GKRS.

Every 1-5 years, imaging and clinical evaluations continued even after proof of obliteration to assess the development of long-term complications. In patients for whom MRI was contraindicated (e.g., in the presence of a cardiac pacemaker), follow-up was performed using CT. Because participating institutions were tertiary referral centers, some patients underwent clinical follow-up evaluations 

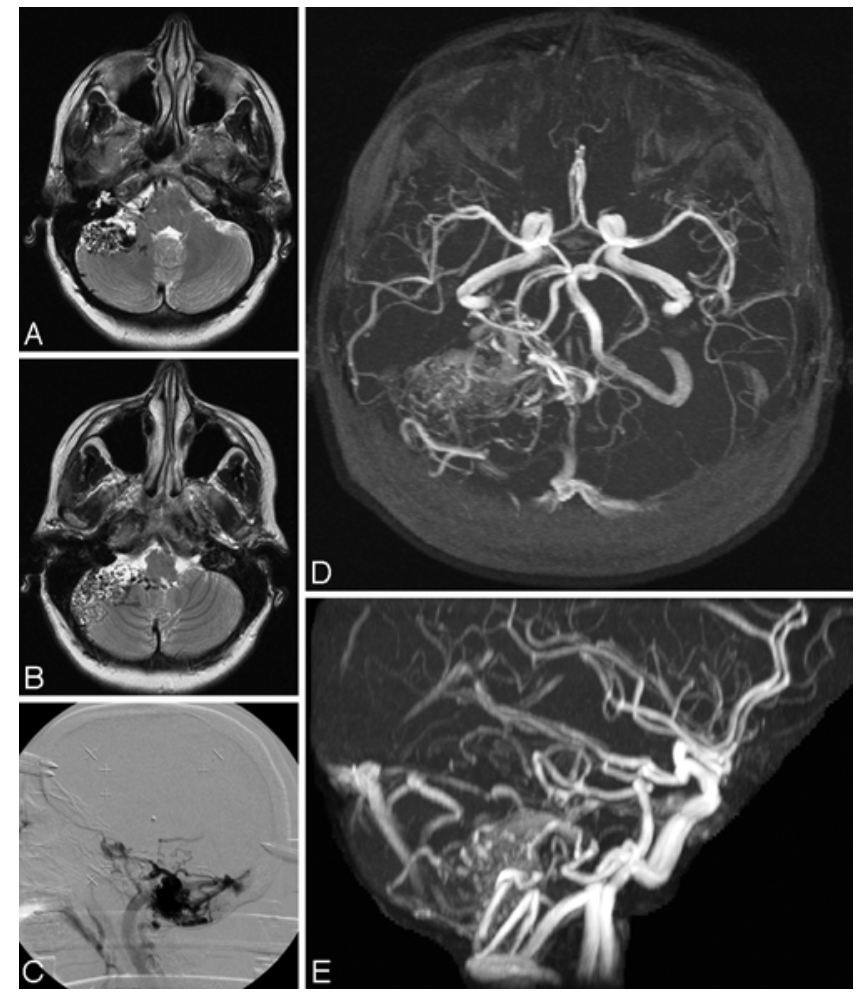

FIG. 1. Case illustration. This 37-year-old woman presented with a posterior fossa hemorrhage from a large-nidus right cerebellar AVM (Spetzler-Martin Grade V, RBAS Score 2.34, VRAS Score 3). A and B: Axial T2-weighted images. C: Lateral angiogram. D and E: 3D MR angiographic reconstruction. The patient was initially treated conservatively (no microsurgery).

performed by their local physicians. For such patients, clinical notes and actual neuroimaging studies (i.e., not just the radiological reports) were received and reviewed by the treating clinicians who performed the SRS procedure. The follow-up images were compared with the images obtained at the time of SRS. A favorable outcome was defined as complete AVM obliteration without latency interval hemorrhage or permanent symptomatic RICs. A case illustration is presented in Figs. 1 and 2.

\section{Statistical Analysis}

Data are presented as the median or mean and range for continuous variables, and as frequency and percentage for categorical variables. Calculations of normality were assessed graphically and statistically. Statistical analysis of categorical variables was carried out using chi-square and Fisher's exact test association as appropriate. Statistics of means were carried out using an unpaired Student ttest, both with and without equal variance (Levene's test) as necessary and Wilcoxon rank-sum tests when variables were not normally distributed. Patient, AVM, and radiosurgical characteristics were assessed in univariate analysis to test covariates predictive of outcome. Clinically significant variables and interaction expansion covariates were further assessed in both multivariable analyses as deemed relevant.

Eloquence (defined as the location in a region of critical
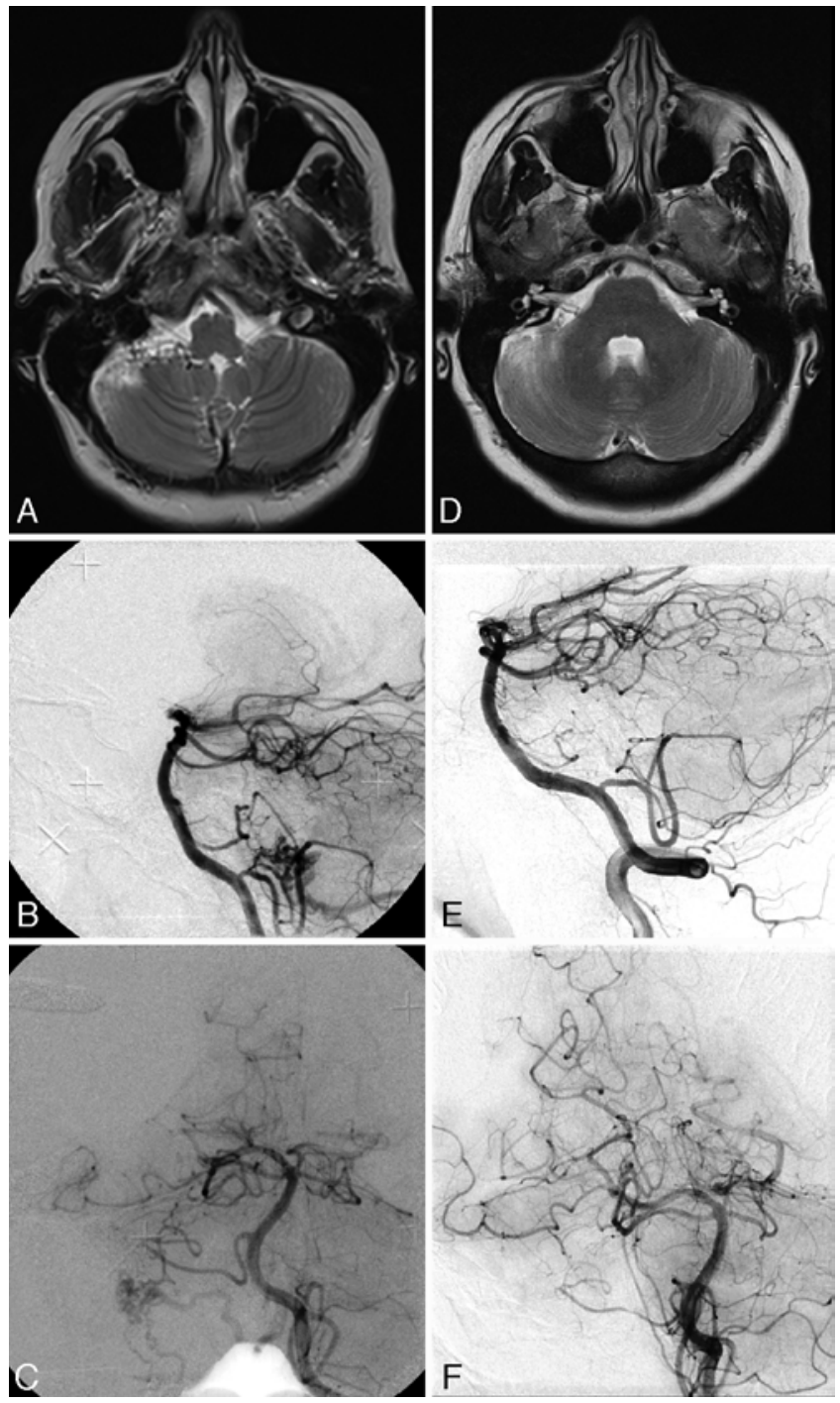

FIG. 2. Case illustration, continued. The patient underwent GKRS in 2007 and again in 2011 for a small remnant nidus. A-C: Axial T2weighted MR image (A), lateral angiogram (B), and anteroposterior angiogram (C) obtained at the time of repeat radiosurgery (2011), showing a substantially smaller nidus retreated. D-F: Axial T2-weighted MR image (D), lateral angiogram (E), and anteroposterior angiogram (F) obtained 22 months after repeat radiosurgery, demonstrating complete AVM nidus obliteration. The patient suffered no latency hemorrhage, symptomatic RICs, or neurological deficits.

neurological importance) was assessed according to the Spetzler-Martin grading scale, ${ }^{31}$ location defined according to the modified RBAS, ${ }^{25}$ and the VRAS. ${ }^{35}$ In addition, competing risk survival analysis of AVM-free obliteration was calculated using the modified Kaplan-Meier method and Gray's method..$^{10}$ After confirming the assumption of proportional hazards, factors predictive of obliteration $(\mathrm{p}$ $<0.15$ ) were entered into modified multivariate Cox regression analysis to assess hazard ratios in the presence of competing mortality risk. ${ }^{9}$ Multivariate regression models and commonly used grading scales were assessed using area under the receiver operating characteristic curve; $p$ values $\leq 0.05$ were considered statistically significant. Sta- 
TABLE 2. Outcomes of patients who underwent SRS for their cerebellar AVMs

\begin{tabular}{lc}
\hline \multicolumn{1}{c}{ Outcome Parameter } & Value \\
\hline Nidus obliteration $(\mathrm{n}=154)$ & \\
\hline Complete obliteration & $87(56.5 \%)$ \\
\hline On MR \& angiography & $18(11.7 \%)$ \\
\hline MR only & $105(68.2 \%)$ \\
\hline Total value & $60(7-325)$ \\
\hline Median time to obliteration (range) in mos & $49(31.8 \%)$ \\
\hline Subtotal/not obliterated & \\
\hline Complications & $9(5.6 \%)$ \\
\hline Post-GKRS hemorrhage $(\mathrm{n}=161)$ & $19(12.3 \%)$ \\
\hline RICs & $18(11.6 \%)$ \\
\hline Total & $7(4.5 \%)$ \\
\hline Radiographic & $2(1.2 \%)$ \\
\hline Symptomatic & $12(7.5 \%)$ \\
\hline Permanent & $56(37.8 \%)$ \\
\hline Mortality $(n=161)$ &
\end{tabular}

* Permanent RICs, or post-SRS latency period hemorrhage, or no nidus obliteration.

tistical analyses were performed using Stata (version 14.0, StataCorp).

\section{Results}

\section{Assessment of Obliteration}

The different outcome parameters are summarized in Table 2. At a median follow-up of 60 months (range 7-325 months), the rate of MRI and/or angiographic-confirmed obliteration was $68.2 \%(n=105)$ at the last follow-up. Complete angiographic obliteration was confirmed in $56.5 \%$ of patients $(\mathrm{n}=87)$, and MRI obliteration was present in another $11.7 \%(\mathrm{n}=18)$. The Kaplan-Meier actuarial rate of obliteration is demonstrated in Fig. 3. The actuarial rates of obliteration at 3,5,7, and 10 years after SRS were $38.3 \%, 74.2 \%, 81.4 \%$, and $86.1 \%$, respectively. As shown in Table 3, patients treated with a higher margin dose were more likely to achieve AVM obliteration. This trend is further emphasized when reviewing patients treated with a margin dose greater than 18 Gy compared with those treated with a margin dose equal to or smaller than $18 \mathrm{~Gy}$ $(50 \%$ [n $=35]$ vs $83.3 \%[\mathrm{n}=70], \mathrm{p}<0.001)$.

Predictors of earlier obliteration in univariate and multivariate Cox regression analyses are summarized in Table 4. In univariate analysis, absence of prior endovascular embolization ( $p=0.006,95 \%$ CI $0.23-0.78)$, a smaller nidus maximal diameter $(\mathrm{p}=0.005,95 \%$ CI $0.49-0.88)$, a higher margin dose ( $\mathrm{p}=0.0001,95 \%$ CI $1.06-1.22)$, and a higher maximal dose $(\mathrm{p}=0.015,95 \%$ CI $1.00-1.07)$ were predictive of nidus obliteration. The Spetzler-Martin scale (each component of the scale and the grade), the presence of any RIC, the VRAS, and the RBAS were not noted to predict obliteration after SRS. In multivariate analysis, prior partial microsurgical resection of the nidus $(\mathrm{p}=0.024$, 95\% CI 1.11-4.68), no prior endovascular embolization ( $\mathrm{p}$

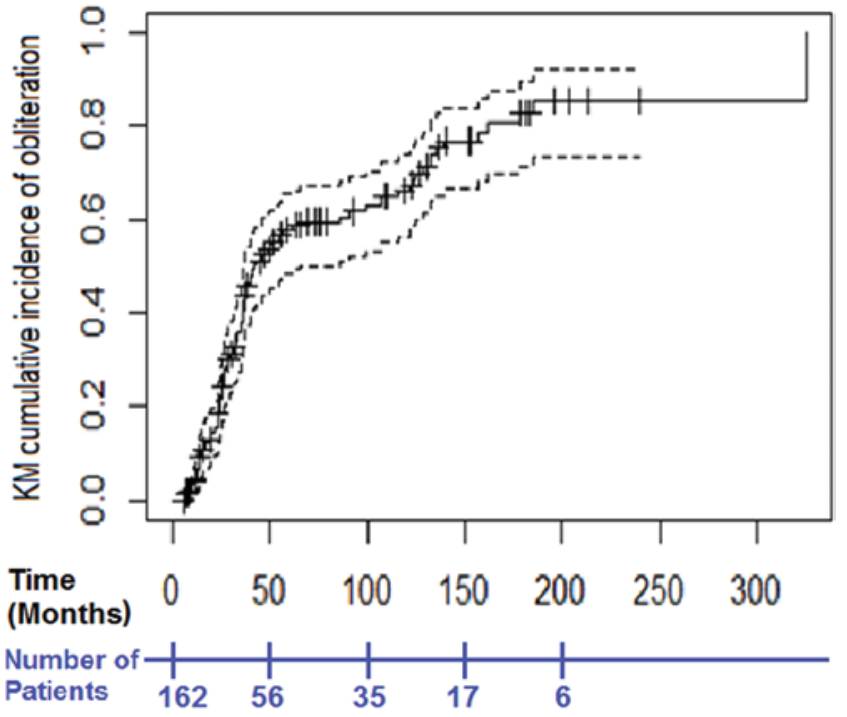

FIG. 3. Kaplan-Meier (KM) plot. Obliteration rate of the cerebellar AVMs each year with $95 \%$ confidence intervals. The actual number of patients at different time points is logged as well. Figure is available in color online only.

$=0.015,95 \%$ CI $0.24-0.86)$, small maximal nidus diameter ( $\mathrm{p}=0.003,95 \%$ CI $0.44-0.85)$, and a higher margin dose $(\mathrm{p}=0.016,95 \%$ CI $1.02-1.19)$ predicted AVM nidus obliteration.

\section{Post-SRS Complications}

Post-SRS latency interval hemorrhage occurred in $5.6 \%(n=9)$ of patients. This result translates to an overall annual hemorrhage incidence of $0.85 \%$. Latency post-SRS hemorrhage was $0.96 \% / y e a r$ in the first 2 years and $0.8 \% /$ year thereafter. No hemorrhages were observed in patients with angiographic or MRI confirmation of obliteration.

RICs were evident on imaging in $12.3 \%(\mathrm{n}=19)$ of patients, symptomatic in $4.5 \%(\mathrm{n}=7)$, and permanent in $1.2 \%(\mathrm{n}=2)$. The risk of RICs as a function of margin dose is presented in Table 2. As noted, no clear correlation to margin dose could be assigned. An RIC did not result in obstructive hydrocephalus in any patient.

\section{Assessment of Favorable Outcome}

Ninety-two patients $(62.2 \%)$ achieved a favorable outcome (i.e., AVM nidus obliteration without latency interval hemorrhage and no permanent SRS-associated RICs). As shown in Table 3, patients treated with a higher margin dose were more likely to achieve a favorable outcome. We found that patients who received an AVM margin dose greater than 18 Gy had a significantly greater likelihood of a favorable outcome compared with patients who received equal to or less than 18 Gy $(52.2 \%[n=35]$ vs $21 \%$ [n $=$ 17], $\mathrm{p}<0.001)$.

Independent predictors of a favorable outcome in univariate and multivariate logistic regression analyses are summarized in Table 4. In multivariate analysis, predictors of a favorable outcome in the multivariate logistic regression analysis were a smaller nidus maximal diameter $(\mathrm{p}=0.001,95 \%$ CI $1.50-4.91)$, the lack of prior endovas- 
TABLE 3. Dose distribution and rates of obliteration, unfavorable outcome, and RICs

\begin{tabular}{|c|c|c|c|c|c|c|c|c|c|}
\hline \multirow[b]{2}{*}{ Dose Distribution (Gy) } & \multicolumn{3}{|c|}{ Obliteration } & \multicolumn{3}{|c|}{ Unfavorable Outcome } & \multicolumn{3}{|c|}{ RIC } \\
\hline & Total & No. & $\%$ & Total & No. & $\%$ & Total & No. & $\%$ \\
\hline$<16$ & 29 & 12 & 41.4 & 27 & 17 & 63 & 29 & 4 & 13.8 \\
\hline $16-18$ & 41 & 23 & 56.1 & 40 & 18 & 45 & 40 & 8 & 20 \\
\hline $18-20$ & 18 & 14 & 77.8 & 15 & 5 & 33.3 & 16 & 1 & 6.3 \\
\hline $20-22$ & 36 & 29 & 80.6 & 36 & 8 & 22.2 & 36 & 5 & 13.9 \\
\hline $22-24$ & 30 & 27 & 90 & 30 & 4 & 13.3 & 31 & 1 & 3.2 \\
\hline$\leq 18$ & 70 & 35 & 50 & 67 & 35 & 52.2 & 69 & 12 & 17.4 \\
\hline$>18$ & 84 & 70 & 83.3 & 81 & 17 & 21 & 83 & 7 & 8.4 \\
\hline Overall & 154 & 105 & 68.2 & 148 & 52 & 35.1 & 152 & 19 & 12.5 \\
\hline
\end{tabular}

"Total" refers to the number of patients treated at the specified dose for whom data are available for the specified variable. "No." refers to the number of patients meeting the variable (obliteration, unfavorable outcome, or RIC). Boldface type indicates trends.

cular embolization ( $\mathrm{p}=0.004,95 \%$ CI $1.57-9.85)$, no prior hemorrhage $(\mathrm{p}=0.009,95 \%$ CI 1.32-7.41), and a higher margin dose $(\mathrm{p}=0.045,95 \%$ CI $0.69-0.99)$.

\section{Discussion}

Cerebellar AVMs provide a challenge for clinical decision making. Such AVMs are associated with a higher risk of hemorrhage in comparison with supratentorial AVMs. ${ }^{4,6,12,29,36,38}$ Although complete surgical removal provides the benefit of early hemorrhage protection, it is associated with a higher risk profile. AVM microsurgery series reviewing all posterior fossa lesions have reported successful obliteration rates of $83 \%-100 \%$, with morbidity rates of $13 \%-25 \%$ and mortality rates of $7 \%-15 \%$ for all Spetzler-Martin grade AVMs. ${ }^{4,716,29}$ Of note, in surgical series, low-grade Spetzler-Martin AVMs formed the bulk of the cohort (62\% of cerebellar AVMs in the study by Rodriquez-Hernandez et al. were Spetzler-Martin Grade I or $\mathrm{II}^{29}$ ), which is similar to our cohort. In addition, endovascular treatment is rarely curative on its own as a primary modality for AVMs, having been shown to be effective in only $10 \%-20 \%$ of cases. ${ }^{24}$ Thus, embolization is typically used as a preoperative adjuvant to either resection or SRS, potentially reducing the nidus target volume to facilitate single-session SRS. ${ }^{30}$ Unfortunately, AVM embolization before SRS has negatively affected obliteration rates. Prior embolization served as a negative predictor of obliteration after SRS in several SRS series. 2,13,21,26,27,35 In addition, AVM embolization (any location) carries a definite risk of complications, exceeding $10 \%$ in some reports. ${ }^{8}$

\section{Radiosurgical Management of Cerebellar AVMs}

A paucity of SRS outcomes data exists for cerebellar AVMs, with most reports constituting highly selective, single-institution series. . $^{74,20,22,40}$ We typically recommend waiting 6-12 weeks between rupture and SRS, allowing for the resolution of blood products that may obscure the borders of the nidus and hamper target delineation. Hemosiderin deposition has also been suggested to increase the radiosensitivity of normal parenchyma. ${ }^{32}$

Ding et al. 7 performed a matched-cohort analysis of 60 cerebellar AVMs treated with SRS to 180 supratentorial, lobar AVMs. ${ }^{7}$ Hemorrhagic presentation was significantly more common in the cerebellar AVM cohort $(\mathrm{p}<0.001)$. The cumulative obliteration rate was $72 \%$, with actuarial obliteration rates at 3 and 5 years of $51 \%$ and $71 \%$, respectively. Younger age $(p=0.019)$, a lack of prior embolization $(\mathrm{p}<0.001)$, and small nidus volume $(\mathrm{p}=0.034)$ were found to be independent predictors of obliteration. Cerebellar location did not affect AVM radiosurgery outcomes.

Bowden et al. ${ }^{4}$ recently reported their institutional experience treating cerebellar AVMs in a cohort of 64 patients; $73 \%$ of patients presented with an intracranial hemorrhage. Deep venous drainage was noted in $66 \%$. The actuarial rates of obliteration at 3, 4, 5, and 10 years were $53 \%, 69 \%, 76 \%$ and $76 \%$, respectively. A permanent neurological deficit due to RICs was reported in 1 patient $(1.6 \%)$ and transient symptomatic RICs were reported in 2 (3.1\%) additional patients. ${ }^{4}$

The diagnosis of an associated aneurysm has been shown by the Toronto study group ${ }^{6}$ as a significant risk factor for hemorrhage. ${ }^{15}$ Bowden et al. ${ }^{4}$ reported an associated aneurysm in $25 \%$ of cerebellar AVMs. Kouznetsov et al. ${ }^{18}$ compared the frequencies of cerebellar AVM prenidal aneurysm-related ruptures in cases of supra- and infratentorial AVMs. Reviewing a cohort of 233 AVMs, the authors reported that $25(11 \%)$ were in the posterior fossa; of these 25 cases, 22 (88\%) presented with hemorrhage, including 9 patients $(41 \%)$ who presented with hemorrhage due to a prenidal aneurysm rupture. Robert et al. ${ }^{28}$ reported a cohort of 55 patients with cerebellar AVMs, with a hemorrhagic presentation reported for $81 \%$ and an associated aneurysm in $45 \%$ of patients. Most authors agree that posterior fossa AVM hemorrhages are frequently associated with prenidal arterial aneurysms, which can be managed by endovascular or microvascular treatment. ${ }^{15,18}$

By combining the outcome data of centers participating in the IGKRF, we report the largest cohort of cerebellar AVMs treated with SRS. The overall actuarial rate of obliteration at 5 years after SRS was $74.2 \%$. Symptomatic RICs developed in $4.5 \%(n=7)$. No patient developed hydrocephalus secondary to SRS perilesional swelling and resultant obstructive hydrocephalus. This fact highlights the relative safety of SRS to this region, despite the oftenvoiced concerns of clinicians related to the delayed risk of hydrocephalus.

The current study also highlights the limitations of the 
TABLE 4. Influential factors of outcome after SRS for cerebellar AVM

\begin{tabular}{|c|c|c|c|c|c|c|}
\hline \multirow[b]{2}{*}{ Potential Factors } & \multicolumn{3}{|c|}{ Univariate Analysis } & \multicolumn{3}{|c|}{ Multivariate Analysis } \\
\hline & OR & $p$ Value & $95 \% \mathrm{Cl}$ & OR & p Value & $95 \% \mathrm{Cl}$ \\
\hline \multicolumn{7}{|l|}{ Influential factors of AVM obliteration $(n=154)^{*}$} \\
\hline Age & 1 & 0.530 & $0.99-1.02$ & & & \\
\hline Sex & 1 & 0.852 & $0.69-1.57$ & & & \\
\hline Prior microsurgery & 1.6 & 0.121 & $0.87-3.14$ & 2.3 & 0.024 & $1.11-4.68$ \\
\hline Prior embolization & 0.4 & 0.006 & $0.23-0.78$ & 0.5 & 0.015 & $0.24-0.86$ \\
\hline Nidus diameter & 0.6 & 0.005 & $0.49-0.88$ & 0.6 & 0.003 & $0.44-0.85$ \\
\hline Treatment vol & 0.9 & 0.155 & $0.87-1.02$ & & & \\
\hline Prior radiotherapy & 1.1 & 0.683 & $0.63-1.99$ & & & \\
\hline Prior hemorrhage & 0.7 & 0.124 & $0.41-1.11$ & & & \\
\hline Margin dose & 1.1 & 0.0001 & $1.06-1.22$ & 1.1 & 0.016 & $1.02-1.19$ \\
\hline Max dose & 1 & 0.015 & $1.00-1.07$ & & & \\
\hline \multicolumn{7}{|l|}{ Spetzler-Martin grade } \\
\hline Overall & 1.1 & 0.617 & $0.83-1.36$ & & & \\
\hline Nidus size & 0.8 & 0.526 & $0.46-1.48$ & & & \\
\hline Eloquence & 1.2 & 0.361 & $0.79-1.87$ & & & \\
\hline Venous drainage & 1.1 & 0.594 & $0.74-1.71$ & & & \\
\hline \multicolumn{7}{|l|}{$\mathrm{RIC}$} \\
\hline Overall & 0.8 & 0.607 & $0.36-1.82$ & & & \\
\hline Radiographic & 0.9 & 0.823 & $0.49-1.76$ & & & \\
\hline Symptomatic & 0.9 & 0.836 & $0.33-2.46$ & & & \\
\hline Permanent & 1.1 & 0.913 & $0.26-4.41$ & & & \\
\hline RBAS & 0.9 & 0.758 & $0.63-1.40$ & & & \\
\hline VRAS & 0.8 & 0.125 & $0.71-1.04$ & & & \\
\hline \multicolumn{7}{|c|}{ Influential factors of unfavorable outcome after AVM SRS $(n=148) \dagger$} \\
\hline Age & 1 & 0.298 & $0.99-1.03$ & & & \\
\hline Sex & 1.3 & 0.491 & $0.64-2.49$ & & & \\
\hline Delay from diagnosis to SRS & 1 & 0.656 & $0.98-1.01$ & & & \\
\hline Prior radiotherapy & 0.4 & 0.121 & $0.98-1.31$ & & & \\
\hline Prior microsurgery & 0.7 & 0.59 & $0.21-2.41$ & & & \\
\hline Nidus treatment vol & 1.4 & 0.0001 & $1.16-1.58$ & & & \\
\hline Max nidus diameter & 3.6 & 0.0001 & $2.05-6.21$ & 2.7 & 0.001 & $1.50-4.91$ \\
\hline Prior embolization & 3.6 & 0.003 & $1.50-7.48$ & 3.9 & 0.004 & $1.57-9.85$ \\
\hline Prior hemorrhage & 4.4 & 0.0001 & $2.08-9.17$ & 3.1 & 0.009 & $1.32-7.41$ \\
\hline Margin dose & 0.8 & 0.0001 & $0.69-0.88$ & 0.8 & 0.045 & $0.69-0.99$ \\
\hline Isocenters & 1.3 & 0.002 & $1.09-1.49$ & 1.4 & 0.006 & $1.09-1.71$ \\
\hline Decreased max dose & 0.9 & 0.009 & $0.89-0.98$ & & & \\
\hline \multicolumn{7}{|l|}{ Spetzler-Martin grade } \\
\hline Overall & 1.4 & 0.134 & $0.91-2.08$ & & & \\
\hline Nidus size & 2.1 & 0.098 & $0.87-5.20$ & & & \\
\hline Eloquence & 1.5 & 0.239 & $0.76-3.02$ & & & \\
\hline Venous drainage & 0.8 & 0.687 & $0.44-1.71$ & & & \\
\hline RBAS & 4.1 & 0.0001 & $1.94-8.79$ & & & \\
\hline VRAS & 3.2 & 0.0001 & $2.02-5.08$ & & & \\
\hline
\end{tabular}

Boldface type indicates statistical significance.

* Cox regression model.

† Logistic regression model. Unfavorable outcome means permanent RIC, post-GKRS hemorrhage, or no obliteration. 
Spetzler-Martin grading system for predicting outcome of cerebellar AVMs after SRS. The Spetzler-Martin scale did not predict obliteration or favorable outcomes. However, both the VRAS and RBAS did predict outcomes after SRS for this cerebellar AVM cohort. We have previously shown the superior validity of the VRAS system over the RBAS. ${ }^{34}$ Our data suggest that the VRAS scale should be used when clinicians attempt to define outcomes of SRS prior to intervention for cerebellar AVMs.

Given the high propensity of cerebellar AVMs to present with hemorrhage, SRS seems to provide significant stabilization of the nidus with an overall cumulative incidence of 5.6\% ( $\mathrm{n}=9)$ for hemorrhage occurring during the latency interval. The annual postradiosurgery hemorrhage rate was $0.85 \%$ prior to obliteration. This compares favorably to a recent meta-analysis of more than 3900 patients that reported an annual hemorrhage risk of $4.5 \%$ for ruptured AVMs and 2.2\% for unruptured lesions. ${ }^{11}$ The complication rate associated with SRS reported in this series is lower than that reported in most microsurgical series. However, this report was not designed to compare SRS to microsurgical outcomes. Surgery is likely used for a different population of cerebellar AVMs.,29

In the context of prospective AVM studies, such as ARUBA (A Randomized Trial of Unruptured Brain AVMs) and the SAIVM (Scottish Audit of Intracranial Vascular Malformations) trial, our findings support the role of SRS in conferring a durable and safe benefit over conservative management for patients with unruptured cerebellar AVMs. One should note, however, that $65.4 \%$ of patients $(n=106)$ in the current study presented with AVM nidus hemorrhage. In addition, some of the patients with unruptured AVMs underwent prior intervention with embolization (22.8\%), fractionated external-beam radiotherapy (9.9\%), and/or microsurgical resection (9.9\%), and would thus be ineligible for ARUBA. The current multicenter cohort clearly defines a role for SRS in management of selected cerebellar AVMs.

\section{Predictors of AVM Radiosurgery Outcomes}

The different independent predictors of overall obliteration in univariate and logistic regression analyses are summarized in Table 4. In keeping with previous reports ${ }^{23}$ both univariate and multivariate analyses support the concept that embolization before SRS negatively predicts AVM obliteration ( $p=0.006$ for univariate analysis and $p=0.015$ for multivariate analysis). In addition, a larger nidus diameter $(\mathrm{p}=0.005$ for univariate analysis and $\mathrm{p}=0.003$ for multivariate analysis) and lower margin dose $(p=0.0001$ for univariate analysis and $p=0.016$ for multivariate analysis) negatively affected results. The current study strongly suggests that greater than $18 \mathrm{~Gy}$ be delivered to a cerebellar AVM at the time of initial SRS to afford a reasonable chance for obliteration. As detailed in Table 3, reviewing the outcome parameters for the entire cohort may mask somewhat the efficacy and safety of SRS treatment with a higher margin dose. Patients treated with a margin dose greater than 18 Gy showed significantly better rates of obliteration and favorable outcome $(83.3 \%$ and $79 \%$, respectively). This dose effect on outcome is further emphasized when reviewing patients treated with a margin dose of 22-24 Gy (90\% and $86.7 \%$, respectively).

Various factors may contribute to the failure of embolization to improve obliteration rates in patients who then undergo SRS. ${ }^{2,25,35}$ Embolization has been shown to promote angiogenesis in AVMs, which may contribute to its failure to achieve complete obliteration. ${ }^{5}$ Pre-SRS embolization can also result in an irregular diffuse nidus architecture, which is difficult to target radiosurgically. ${ }^{37}$ The use of dense radiopaque liquid adhesives often makes imaging of the remaining nidus problematic.

\section{Study Limitations}

This study represents the largest series presented to date of cerebellar AVMs treated with SRS. However, analysis remains limited by the retrospective nature of the data collected from each of the participating institutions. Some of the data (particularly from the University of Pittsburgh and the University of Virginia) were previously used to construct SRS AVM grading schemes (the RBAS and the VRAS, respectively). These overlapping cohorts represent a potential source for bias, but the length of follow-up in the current cohort is longer than those used to derive the original grading scales.

Although only $82.1 \%$ of cases of obliteration in this study were confirmed by angiography (MRI has been shown to be a reasonable substitute for angiography in determining obliteration in remaining patients), ${ }^{19}$ an additional study limitation stems from the varied SRS treatment strategies used in different Gamma Knife centers. These differences may manifest in a higher or a lower standard nidus prescription dose, or smaller/larger nidus coverage. We believe that despite its limitations, this study's multicenter design allows our findings to be generalizable to most AVM patients being considered for radiosurgery.

\section{Conclusions}

The treatment of cerebellar AVMs is a formidable challenge due to the higher risk of morbidity and mortality of infratentorial AVMs. SRS, particularly with a dose greater than $18 \mathrm{~Gy}$, affords high rates of nidus obliteration with an acceptable low incidence of latency period hemorrhage or permanent complications in the majority of patients treated. Despite different anatomical and angioarchitectural variations, SRS outcomes do not seem to be affected by cerebellar location. This finding contrasts those reported in microsurgical series where cerebellar location bore a negative prognostic effect. Radiosurgical grading systems such as VRAS (but not the Spetzler-Martin scale) provide a method to predict the long-term outcome for cerebellar AVM patients treated with SRS.

\section{Acknowledgments}

We acknowledge the assistance of Lisa Baxendall, the clinical coordinator for the IGKRF.

\section{References}

1. Al-Shahi R, Bhattacharya JJ, Currie DG, Papanastassiou V, 
Ritchie V, Roberts RC, et al: Prospective, population-based detection of intracranial vascular malformations in adults: the Scottish Intracranial Vascular Malformation Study (SIVMS). Stroke 34:1163-1169, 2003

2. Andrade-Souza YM, Ramani M, Scora D, Tsao MN, terBrugge K, Schwartz ML: Embolization before radiosurgery reduces the obliteration rate of arteriovenous malformations. Neurosurgery 60:443-451, 2007

3. Arnaout OM, Gross BA, Eddleman CS, Bendok BR, Getch $\mathrm{CC}$, Batjer HH: Posterior fossa arteriovenous malformations. Neurosurg Focus 26(5):E12, 2009

4. Bowden G, Kano H, Tonetti D, Niranjan A, Flickinger J, Lunsford LD: Stereotactic radiosurgery for arteriovenous malformations of the cerebellum. J Neurosurg 120:583-590, 2014

5. Buell TJ, Ding D, Starke RM, Webster Crowley R, Liu KC: Embolization-induced angiogenesis in cerebral arteriovenous malformations. J Clin Neurosci 21:1866-1871, 2014

6. da Costa L, Thines L, Dehdashti AR, Wallace MC, Willinsky RA, Tymianski M, et al: Management and clinical outcome of posterior fossa arteriovenous malformations: report on a single-centre 15-year experience. J Neurol Neurosurg Psychiatry 80:376-379, 2009

7. Ding D, Starke RM, Yen CP, Sheehan JP: Radiosurgery for cerebellar arteriovenous malformations: does infratentorial location affect outcome? World Neurosurg 82:e209-e217, 2014

8. Ding D, Yen CP, Xu Z, Starke RM, Sheehan JP: Radiosurgery for patients with unruptured intracranial arteriovenous malformations. J Neurosurg 118:958-966, 2013

9. Fine JP, Gray RJ: A proportional hazards model for the subdistribution of a competing risk. J Am Stat Assoc 94:496509,1999

10. Gray RJ: A class of K-sample tests for comparing the cumulative incidence of a competing risk. Ann Stat 16:1141-1154, 1988

11. Gross BA, Du R: Natural history of cerebral arteriovenous malformations: a meta-analysis. J Neurosurg 118:437-443, 2013

12. Hernesniemi JA, Dashti R, Juvela S, Väärt K, Niemelä M, Laakso A: Natural history of brain arteriovenous malformations: a long-term follow-up study of risk of hemorrhage in 238 patients. Neurosurgery 63:823-831, 2008

13. Kano H, Kondziolka D, Flickinger JC, Park KJ, Iyer A, Yang $\mathrm{HC}$, et al: Stereotactic radiosurgery after embolization for arteriovenous malformations. Prog Neurol Surg 27:89-96, 2013

14. Kano H, Kondziolka D, Flickinger JC, Yang HC, Flannery TJ, Awan NR, et al: Stereotactic radiosurgery for arteriovenous malformations, Part 3: outcome predictors and risks after repeat radiosurgery. J Neurosurg 116:21-32, 2012

15. Kano H, Kondziolka D, Flickinger JC, Yang HC, Park KJ, Flannery TJ, et al: Aneurysms increase the risk of rebleeding after stereotactic radiosurgery for hemorrhagic arteriovenous malformations. Stroke 43:2586-2591, 2012

16. Kelly ME, Guzman R, Sinclair J, Bell-Stephens TE, Bower R, Hamilton S, et al: Multimodality treatment of posterior fossa arteriovenous malformations. J Neurosurg 108:11521161,2008

17. Khaw AV, Mohr JP, Sciacca RR, Schumacher HC, Hartmann A, Pile-Spellman J, et al: Association of infratentorial brain arteriovenous malformations with hemorrhage at initial presentation. Stroke 35:660-663, 2004

18. Kouznetsov E, Weill A, Ghostine JS, Gentric JC, Raymond J, Roy D: Association between posterior fossa arteriovenous malformations and prenidal aneurysm rupture: potential impact on management. Neurosurg Focus 37(3):E4, 2014

19. Lee CC, Reardon MA, Ball BZ, Chen CJ, Yen CP, Xu Z, et al: The predictive value of magnetic resonance imaging in evaluating intracranial arteriovenous malformation oblitera- tion after stereotactic radiosurgery. J Neurosurg 123:136144, 2015

20. Maruyama K, Kawahara N, Shin M, Tago M, Kishimoto J, Kurita H, et al: The risk of hemorrhage after radiosurgery for cerebral arteriovenous malformations. N Engl J Med 352:146-153, 2005

21. Miller RA, Jankowitz B: Endovascular embolization in combination with radiosurgery for treatment of arteriovenous malformations. Prog Neurol Surg 27:81-88, 2013

22. Monaco EA III, Niranjan A, Kano H, Flickinger JC, Kondziolka D, Lunsford LD: Management of adverse radiation effects after radiosurgery for arteriovenous malformations. Prog Neurol Surg 27:107-118, 2013

23. Ondra SL, Troupp H, George ED, Schwab K: The natural history of symptomatic arteriovenous malformations of the brain: a 24-year follow-up assessment. J Neurosurg 73:387391, 1990

24. Panagiotopoulos V, Gizewski E, Asgari S, Regel J, Forsting M, Wanke I: Embolization of intracranial arteriovenous malformations with ethylene-vinyl alcohol copolymer (Onyx). AJNR Am J Neuroradiol 30:99-106, 2009

25. Pollock BE, Flickinger JC: Modification of the radiosurgerybased arteriovenous malformation grading system. Neurosurgery 63:239-243, 2008

26. Pollock BE, Flickinger JC, Lunsford LD, Maitz A, Kondziolka D: Factors associated with successful arteriovenous malformation radiosurgery. Neurosurgery 42:1239-1247, 1998

27. Pollock BE, Gorman DA, Brown PD: Radiosurgery for arteriovenous malformations of the basal ganglia, thalamus, and brainstem. J Neurosurg 100:210-214, 2004

28. Robert T, Blanc R, Ciccio G, Redjem H, Fahed R, Smajda S, et al: Anatomic and angiographic findings of cerebellar arteriovenous malformations: Report of a single center experience. J Neurol Sci 358:357-361, 2015

29. Rodríguez-Hernández A, Kim H, Pourmohamad T, Young WL, Lawton MT: Cerebellar arteriovenous malformations: anatomic subtypes, surgical results, and increased predictive accuracy of the supplementary grading system. Neurosurgery 71:1111-1124, 2012

30. Sirin S, Kondziolka D, Niranjan A, Flickinger JC, Maitz AH, Lunsford LD: Prospective staged volume radiosurgery for large arteriovenous malformations: indications and outcomes in otherwise untreatable patients. Neurosurgery 58:17-27, 2006

31. Spetzler RF, Martin NA: A proposed grading system for arteriovenous malformations. J Neurosurg 65:476-483, 1986

32. St George EJ, Perks J, Plowman PN: Stereotactic radiosurgery XIV: The role of the haemosiderin 'ring' in the development of adverse reactions following radiosurgery for intracranial cavernous malformations: a sustainable hypothesis. Br J Neurosurg 16:385-391, 2002

33. Stapf C, Mast H, Sciacca RR, Choi JH, Khaw AV, Connolly ES, et al: Predictors of hemorrhage in patients with untreated brain arteriovenous malformation. Neurology 66:1350-1355, 2006

34. Starke RE, Kano H, Ding D, Lee JY, Mathieu D, Whitesell J, et al: Stereotactic radiosurgery for arteriovenous malformations: a multicenter evaluation of grading scales and longterm outcomes. J Neurosurg [epub ahead of print March 4, 2016. DOI: 10.3171/2015.9.JNS151311]

35. Starke RM, Yen CP, Ding D, Sheehan JP: A practical grading scale for predicting outcome after radiosurgery for arteriovenous malformations: analysis of 1012 treated patients. J Neurosurg 119:981-987, 2013

36. Tong X, Wu J, Lin F, Cao Y, Zhao Y, Ning B, et al: The effect of age, sex, and lesion location on initial presentation in patients with brain arteriovenous malformations. World Neurosurg 87:598-606, 2016

37. Valle RD, Zenteno M, Jaramillo J, Lee A, De Anda S: Defini- 
tion of the key target volume in radiosurgical management of arteriovenous malformations: a new dynamic concept based on angiographic circulation time. J Neurosurg 109 Suppl:41-50, 2008

38. Yamada S, Takagi Y, Nozaki K, Kikuta K, Hashimoto N: Risk factors for subsequent hemorrhage in patients with cerebral arteriovenous malformations. J Neurosurg 107:965972, 2007

39. Yaşargil MG: Microneurosurgery. New York: Thieme, 1998, Vol IIIB

40. Yen CP, Schlesinger D, Sheehan JP: Natural history of cerebral arteriovenous malformations and the risk of hemorrhage after radiosurgery. Prog Neurol Surg 27:5-21, 2013

\section{Disclosures}

The authors report the following. Dr. Grills: direct stock ownership in and executive board of directors for Greater Michigan Gamma Knife. Dr. Lunsford: consultant for Elekta AB, Best Doctors, and Advance Medical; and direct stock ownership in Elekta AB.

\section{Author Contributions}

Conception and design: Cohen-Inbar, Sheehan. Acquisition of data: Cohen-Inbar, Starke, Kano, Bowden, Huang, RodriquezMercado, Almodovar, Grills, Mathieu, Silva, Abbassy, Missios, Lee. Analysis and interpretation of data: Cohen-Inbar. Drafting the article: Cohen-Inbar. Critically revising the article: CohenInbar, Starke, Barnett, Kondziolka, Lunsford, Sheehan. Reviewed submitted version of manuscript: Cohen-Inbar, Kano, Bowden, Huang, Rodriquez-Mercado, Almodovar, Grills, Mathieu, Silva, Abbassy, Missios, Lee, Barnett, Kondziolka, Lunsford, Sheehan. Approved the final version of the manuscript on behalf of all authors: Cohen-Inbar. Statistical analysis: Starke. Administrative/ technical/material support: Sheehan. Study supervision: Sheehan.

\section{Correspondence}

Or Cohen-Inbar, Department of Neurological Surgery, University of Virginia Health System, Box 800212, Charlottesville, VA 22908. email: oc2f@virginia.edu. 